\title{
Gender Norms and Gender Inequality in Unpaid Domestic Work among Malay Couples in Malaysia
}

\author{
Harn Shian Boo \\ Anthropology and Sociology Section, School of Social Sciences, Universiti Sains Malaysia, 11800 Pulau \\ Pinang, Malaysia
}

\begin{abstract}
This article explores how gender norms rooted in culture and religion influence gender inequality among Malay couples in Malaysia. Studies on the unbalanced division of unpaid domestic work are pivotal because they negatively affect women's economic status, wellbeing and life. Many studies have indicated that gender inequality in the division of household labour persists even after accounting for paid work time and resources, suggesting that gender norms lead to the unequal division in unpaid domestic work. By using gender perspective as the theoretical perspective, this study explores how men and women behave according to cultural and religious defined gender roles and are expected to behave as such. In this qualitative study, semi-structured interviews were conducted with nine Malay couples in Malaysia. The study suggests that women shoulder a disproportionate amount of housework and childcare due to the cultural and religious gender norms that foster the prescribed roles, emphasising men's role as the primary breadwinners and women's role as the homemakers. This study highlights that gender norms rooted in culture and religion plays vital roles in creating gender inequality among Malay couples. Moreover, this study adds support to the gender perspective that not only gender role ideology matter, but also highlights that religiosity matters when accounting for gender norms in Malay society. This study implies that recognising the importance of cultural and religious gender norms around domestic work as women's work is crucial in narrowing the gender gap in unpaid domestic work.
\end{abstract}

ARTICLE INFO

Article history:

Received: 01 May 2021

Accepted: 14 October 2021

Published: 03 December 2021

DOI: https://doi.org/10.47836/pjssh.29.4.14

E-mail address:

booharnshian@usm.my
Keywords: Gender inequality, gender norms, Malaysia, unpaid domestic work

\section{INTRODUCTION}

Over the years, unpaid domestic work, including housework and childcare, has been shouldered by women rather than men in Malaysia despite increases in 
women's educational attainment and labour force participation (Choong et al., 2019; Ministry of Women, Family and Community Development and the United Nations, 2014). Studies on housework in Malaysia have generally found that women are responsible for most of the housework, whereas men spend less time on it (Boo, 2018; Choong et al., 2019; Jamil et al., 2018). Studies on childcare in Malaysian families have generally suggested that mothers spend significantly more time on childcare than fathers (Boo, 2018; Choong et al., 2019; Juhari et al., 2013). Hence, these conclusions suggest that gender inequality in unpaid domestic work, where the proportion of time spent is disaggregated by gender, exists in Malaysian families. In this study, gender inequality refers to the social process by which individuals experience unequal treatment or perceptions based on their gender (Adams, 2017; Wood, 2014). In this context, gender inequality means women are experiencing unequal treatment in their households because of their gender despite their educational attainment and labour force participation.

Studies on unpaid domestic work are pivotal because the unequal division of household labour negatively affects women's economic status, well-being and life in general. For example, women who devote more time to unpaid domestic work are more likely to earn lower incomes than men (Choong et al., 2019). In addition, performing housework and childcare is a burden, especially for married working women, because they often must work a 'second shift' (Choong et al., 2019). Women are expected to perform housework and childcare at home after completing paid employment (Hochschild \& Machung, 2012). Moreover, women who struggle to balance work and family responsibilities are more likely to experience negative well-being (N. N. A. Aziz et al., 2016, 2018). Due to the burden and difficulties of balancing work and family responsibilities, most women chose family responsibilities as the main reason as to why they were unemployed (Department of Statistics Malaysia, 2019).

Studies in Malaysia have suggested that women's paid work hours and income are two critical factors in narrowing the gender gap in the division of household labour among heterosexual couples (Boo, 2018). It means that husbands increase their share of housework and childcare when their wives spend more time engaging in paid work and have higher incomes than they do. In addition, Choong et al. (2019) suggested that income classes influence women's time spent on unpaid domestic work, i.e. women in higher-income classes spent less time on unpaid domestic work than women in lowerincome classes (Choong et al., 2019).

Even after accounting for paid work hours and income, gender inequality persists in Malaysian households (Boo, 2018). Very few studies suggest that gender inequality at home may be related to gender norms in Malaysia (Juhari et al., 2013) and globally (Ferrant et al., 2014; Kaufman, 2014; Stratton, 2020; United Nations Population Fund [UNFPA] \& Promundo, 2018) which 
could explain why gender inequality in households remains. In this study, gender norms are the expectations that determine and regulate appropriate behaviour for women and men in societies (Cislaghi \& Heise, 2020). For example, women are the homemakers and do unpaid domestic work; whereas, men are the breadwinners and do not do unpaid domestic work. Norms allow men not to do housework and childcare. For men, being responsible for unpaid domestic work is not socially acceptable in many societies and is considered against the norms (UNFPA \& Promundo, 2018), which places women in a disadvantaged position in families and reinforces gender inequality in the households over generations.

In the context of the Malay family structure in Malaysia, such gender norms are often emphasised in Malay culture and also embedded in Islamic teachings that men are the primary providers, protectors and heads of families (Ismail \& Hamjah, 2012; Osman, 2013; Sukri \& Shasrini, 2020) and women are responsible for the husband, children and housework. Thus, employed Malay women are supposed to put family first and work second, even when they make a financial contribution to the household (Abdullah et al., 2008; Noor, 1999). As a result, women and men are socialised into socially and culturally defined roles: women are expected to perform most unpaid work. Men are expected to play the backup role because their primary role is being the breadwinners. Hence, because of the prescribed backup role defined by gender norms, men only engage in unpaid work when they have free time or when requested by their spouses. In short, gender norms become a barrier to achieving gender equality in households if women and men behave according to culture and religion prescribed roles (Kaufman, 2014; UNFPA \& Promundo, 2018). It should be highlighted that prescribed roles embedded in the cultural gender norms, with the traditional model of the man as breadwinner and women as a homemaker, are similar to the prescribed roles in religious gender norms embedded in the Islamic teachings: women's duties in unpaid domestic work and men's duties in providing for and protecting their families. Both cultural and religious gender norms encourage women and men to take on different roles based on their gender.

\section{LITERATURE REVIEW}

Three theoretical perspectives dominate the empirical literature on unpaid domestic work: (1) time availability, (2) relative resources and (3) gender perspectives. The time availability perspective argues that the gender division of household labour is based on a rational decision of who has more time for household work (Coverman, 1985). This perspective suggests that paid work hours reduce the time available for unpaid domestic work. One spouse will perform more unpaid domestic work than the other spouse if the latter does not have time to perform unpaid domestic work, regardless of gender. Most studies have found that women reduce their time spent in housework and childcare when they engage in paid employment (Bianchi et al., 2000; Boo, 2018; Craig \& Brown, 2017). 
Next, the relative resources perspective argues that the division of household labour is a rational process leading to a 'fair' exchange between couples (Blood $\&$ Wolfe, 1960). This perspective suggests that power dynamics shape the division of household labour between partners based on the relative resources that each brings into the household. Studies have demonstrated a positive association between income resources and time spent on household work (Boo, 2018; Carlson \& Lynch, 2017).

However, even after accounting for paid work time and income resources in the division of household labour, full-time working women report that they perform more unpaid work than their spouses do (Bittman et al., 2003; Sayer, 2016). Scholars have argued that gender matters most in explaining the unequal division of household labour (Bianchi et al., 2000; Coltrane, 2000). The gender perspective argues that men and women are socialised into male and female gender roles through socialisation and are expected to behave based on the gender norms (Cunningham, 2001; Epstein \& Ward, 2011).

In addition to the socialisation of gender norms, the gender perspective argues that individuals' gender role ideology also matters in the division of unpaid domestic work. Gender role ideology defines an individual's attitudes to how women and men play their roles are shaped by their sex (Somech \& Drach-Zahavy, 2016). Gender role ideology is situated on a continuum that ranges from traditional (i.e., the male-breadwinner and femalehomemaker model) to egalitarian (i.e., a shared responsibility between spouses). The gender perspective predicts that women who hold a more traditional gender ideology will perform more unpaid domestic work than women who hold a more egalitarian gender ideology; by contrast, men who hold a more traditional gender ideology will perform less unpaid domestic work than men who hold a more egalitarian gender ideology (Coltrane, 2000; Knudsen \& Wærness, 2008). Overall, the gender perspective argues that the power of gender norms and gender role ideology may explain gender inequality in unpaid domestic labour.

The research gap includes very few topics related to gender norms that have been explored in unpaid domestic work, which emphasises the traditional malebreadwinner and female-homemaker model (Juhari et al., 2013; Kaufman, 2014; UNFPA \& Promundo, 2018). Second, the persistence of gender inequality in Malaysian households shows the importance of using gender perspective as the theoretical perspective in the Malaysian context to understand unpaid domestic work among couples through a qualitative approach. Therefore, to fill the research gap, this study used the gender perspective to examine how gender norms rooted in culture and religion influence gender inequality among Malay couples in Malaysia. In general, this study supports the gender perspective that unequal division of household labour is related to the prescribed role emphasised in the gender norms. This study contributes to the gender perspective that gender norms rooted in culture and religion play vital roles in creating gender inequality in households. In addition, this 
study contributes to the gender perspective that not only does gender role ideology matter but also highlights that religiosity matters when accounting for gender norms in Malay society.

\section{METHODOLOGY}

This study adopted the qualitative approach to examine women's and men's roles and who should perform the unpaid domestic work among nine Malay couples in Malaysia. A semi-structured interview tool was used to collect data. The interview questions include women's and men's roles and responsibilities and the reasons for doing housework and childcare.

The respondents' inclusion criteria, using purposive sampling, were Malay married couples living with children under 12. The sample of respondents was selected based on their criteria and interests to take part in this study via social media. This study protocol was approved by the University of New South Wales Human Ethics Board (Approval number: HC11272). The couples were interviewed face-to-face for 60 to 90 minutes in their homes. In addition, each spouse was interviewed separately to capture their perceptions and experiences without the influence of the other. The interviews were tape-recorded upon the consent provided by the interviewees. A voucher was given to interviewees for their time in participating in this research. The names of respondents were replaced with pseudonyms. The interview data were analysed using a thematic approach. First, interviews data was reviewed according to codes to find themes. Then, all the themes were reviewed and named accordingly to address the research issues.

All interviewees were in their thirties. The typical household comprised a spouse (one male and one female) and one or two children. Most of the interviewees had at least a bachelor's degree. All the couples lived in urban areas. All the male interviewees worked full-time outside the home. Of the nine female interviewees, three worked full-time outside the home, three worked part-time outside the home, and three worked full-time for their households. Most women perceived themselves as very religious among all interviewees, and about half of the men perceived themselves as very religious. In this study, religiosity (strength of religious beliefs) is self-defined by respondents based on their frequency of prayers, frequency of going to the mosque and religiosity piety. For example, respondents who go to mosque and pray frequently and follow most religious practices are considered themselves as very religious. In contrast, those who do not go to the mosque and pray frequently and do not follow most religious practices are considered less religious.

\section{FINDINGS}

This study collected data from interviews of nine married Malay couples. The findings suggest a primary theme: cultural gender norms that champion the traditional malebreadwinner and female-homemaker model causes unequal division of housework and childcare among couples. In addition to 
the cultural gender norms, religious gender expectations embedded in Islamic teachings also restrict couples from sharing unpaid domestic work equally. However, the experience varies between men and women. For example, more religious women tend to have a traditional gender role ideology; hence, they perform a disproportionate unpaid work. In contrast, more religious men tend to have an egalitarian gender role ideology and are willing to share the burden, whereas, less religious men tend to have a traditional gender ideology to play a backup role.

\section{Cultural Gender Norms: Traditional Male-Breadwinner and Female- Homemaker Model}

The data from the interviews demonstrated that women are expected to perform most of the housework and childcare and support their families through unpaid labour. In contrast, men are expected to be employed and support their families financially.

"I think in Malay families, men go to work and women stay at home to look after the children." Nana, part-time employment, very religious.

"I think it has become a norm in our society that a husband should work to support the family and a wife should take care of the household work." - Aisha, fulltime employment, very religious.

"Malay [culture] says that it is the wife's responsibility to do housework and we have to do it sincerely." - Fatimah, part-time employment, somewhat religious.

The quotes of Nana and Aisha suggest that women and men hold different family roles, which are aligned with cultural gender norms in Malay society. This finding was further illustrated by Fatimah's quote describing that her responsibility as a wife is to perform housework 'sincerely'. The word 'sincerely' suggests that because she is obliged by Malay cultural gender norms to perform housework, she must be genuine in doing so and may not question its rightness. Thus, this example portrays how gendered expectations among Malay families may influence Malay women to perform more household labour than men.

Similar descriptions were provided by most of the Malay men in the study. They stated that men are responsible for earning money and that women are responsible for household work. These men had consistent views on gender roles irrespective of the strength of their religious beliefs.

"This is Malay custom. When we are married, the husband needs to work outside and the wife needs to handle the household work. It is my responsibility to work, not her responsibility to work. This practice remains unchanged." - Keri, fulltime employment, very religious.

"It is my responsibility to work. My wife does not need to work because I can afford the family 
expenditures." - Nazri, full-time employment, less religious."

"As a wife, she has to be good in doing housework and managing household matters. A wife has her own responsibility at home," Tramizi, full-time employment, very religious.

The quotes illustrate higher expectations that men will be the breadwinner and lower expectations that they will be involved in housework. Men will likely play a backup role in performing housework if they are not expected to be mainly responsible for the unpaid work. In addition, the quotes reveal the gender expectations that women will be full-time homemakers and mothers rather than be employed. The link between paid and unpaid work that may cause the unequal division of housework and childcare can also be observed in how Malay men have the final authority over whether their wife is employed. Most interview quotes show how Malay husbands use their authority to influence whether their wife is employed. Azizah talking about her husband, Keri, is an example:

\section{"I discussed with my husband} whether I should work or not. He prefers me to stay at home and look after the children and him. When he gets home, I have already prepared the meals and drinks for him. He prefers me to take care of them instead of working outside."

- Azizah, full-time homemaker, very religious.
Azizah followed her husband's decision to not engage in employment but spend time preparing meals for the family and taking care of the children. Her description of her husband's authority is consistent with what her husband, Keri, said:

"I made the final decision. I wanted her to stay at home and not work after we got married. It is my responsibility to earn income, not her responsibility. I really do not encourage my wife to engage in any employment. I prefer her to stay at home, look after the children, and look after our food and drinks." Keri, full-time employment, very religious.

Azizah had not been employed since graduating from high school. She became a full-time mother because her husband, Keri, preferred her not to work outside the home. They believed that taking care of the housework and children were responsibilities for women, not men. From how Azizah described her responsibilities, it is not surprising that she performed more housework and childcare than her husband, Keri. Notably, their lifestyle was not luxurious; however, Keri thought the family could live modestly on one income (i.e. MYR 2250 per month). This choice implies they preferred to follow cultural gender norms that emphasise the traditional male-breadwinner and female-homemaker model.

Reinforcing the male-breadwinner and female-homemaker pattern, most Malay 
women interviewed planned to stop working when they felt their husbands could support their families.

\section{"Malay people say that no matter} how clever a wife is, her place is still in the kitchen. If a wife is not good at doing kitchen work, the family will have problems. If a wife cannot cook for the family, what is the point to marry a wife? I wanted to get married, so my wife had to cook for me. A wife needs to clean the house so that it is tidy and wellorganised." - Tramizi, full-time employment, very religious."

The quote from Tramizi suggests that in Malay society, Malay men expect women to perform housework. Malay men perceive that a woman's place remains in the kitchen, regardless of her intellect. Tramizi explained that 'clever' refers to a woman's educational level. He implies that Malay women may not opt-out of housework tasks even if they have high education. Tramizi's quote suggests that Malay culture places less value on women's education and more value on their performing housework. Tramizi's description of women's role alligns with the Malay traditional cultural norm, "women, no matter how highly educated they are, their place is still in the kitchen." (Abdullah et al., 2008, p. 14; Hamdan, 2009, p. 196).

Similar to Tramizi, Shila stated that Malay women are responsible for taking care of the children in Malay families regardless of how successful they are in their careers.
"I think it is common in Malay families that no matter how high position a woman in workplace, her responsibility is still as a wife to take care of the children." Shila, full-time employment, very religious."

Shila reported that she did more housework and childcare than her husband despite having a doctoral degree and working as a university lecturer. She was restricted by the Malay cultural norms that strongly endorse women's household responsibilities despite their qualifications and careers. Shila's description of how Malay cultural norms affected her engagement in housework is similar to Tramizi.

Thus far, the findings suggest that Malay cultural gender norms strongly endorse that women stop working and become full-time homemakers and mothers when their husbands can support the family. In addition, Malay men expressed strong preferences that women should not engage in employment and that men should have the final authority in making that decision. This finding suggests that women are not expected to be the sole or co-provider but should stop working because a wife performing her role in housework and childcare is more highly valued by Malay society than achieving higher educational levels and pursuing a career.

These findings demonstrate that Malay women believe that their primary role is taking care of the housework and children at home; men's primary role is earning money 
in the labour force; these findings support those in the literature (Abdullah et al., 2008; Noor, 1999). In addition, Malay husbands' preference for their wives' employment in this study is similar to that found in the literature (A. Aziz, 2011; Noor, 1999). Thus, although the qualitative results on cultural gender norms and practices of this study cannot be generalised to the whole population, they are consistent with those of studies of Malaysia.

\section{Religious Gender Norms: Women's Duties in Unpaid Domestic Work}

Most of the Malay women interviewees described religion as very important to them in the division of housework. All of the Malay women considered themselves very religious Muslims. They claimed that religion is very important in their personal lives and lived according to Islamic religious teachings. Perhaps the best quotes to show that Islamic religious teachings are the guiding principles in everyday life for Malay women were from Sazlina and Aisha.

"I think for Muslims, your religion is your way of living so it involves all aspects of life. We not only pray and talk about religious teachings daily, how we behave is based on the religious teachings. " Sazlina, full-time homemaker, very religious."

"I think it influences me. We have our responsibility as stated in the religion. When I die, I will face Allah and answer him." -
Aisha, full-time employment, very religious."

These quotes suggest Islamic religious teachings are the guiding principles for Malay women's daily lives. Aisha's quote also suggests that the women believe their daily behaviour influences their afterlife; further, they will be rewarded by Allah if they fulfil their responsibility as stated in their religion (Tajmazinani, 2021). Almost all the Malay women who considered themselves very religious claimed that they do more housework than their spouse because, according to Islamic religious teachings, they are responsible for it as a wife.

"In Islam, it is the wife's responsibility to do housework. If the husband wants to help, it is his willingness to help. It really depends on his willingness." Azizah, full-time homemaker, very religious.

"I think it is because my religion says that I have to be a good wife means I have to make my husband happy. Entertaining a husband means doing something that will make him happy. I think that performing housework and making sure that the house is clean and a nice place to live is a way to make him happy. I think this is the reason why I do housework more." - Shila, full-time employment, very religious. 
The way Azizah and Shila described that their religion expected them to do more housework as a good wife and put less emphasis on their spouse helping with housework suggests that gendered expectations in religious teachings play a greater role in influencing women's than men's contribution to housework.

The gendered expectations regarding housework are consistent, with most Malay women claiming that they did more housework than their spouses. Since all the Malay women in this qualitative study considered themselves very religious in their perceptions and religious activities in their daily lives, it is not clear how less religious Malay women believe that religion influences their division of household chores. However, this phenomenon can be understood through Malay men's experiences.

Malay men were divided evenly between those who considered themselves very religious and those who considered themselves less religious. Comparing the responses of these two groups suggests that they held different attitudes on how religion influences their personal lives and household labour. For example, Ahmad, who reported himself to be very religious, said:

"As a Muslim, Ifollow the religious teachings completely. I go to mosque regularly and discuss it frequently with my wife." - Ahmad, full-time employment, very religious.

Two Malay men who considered themselves less religious, Jamal and Nazri, said:
"I am not religious. There are a lot of things I do not follow. I do not think I can consider myself religious just by praying." - Jamal, full-time employment, less religious.

"I have some religious knowledge, but I do not practise all of them. I do not go to mosque frequently." - Nazri, full-time employment, less religious.

These quotes suggest different practices from Malay men of differing religiosity. Ahmad, very religious, follows the Islamic religious teachings closely and discusses them with his wife. It reinforces the quotes above from Malay women who are very religious. In contrast with Ahmad, the less religious men, Jamal and Nazri, did not perceive religious teachings as their guiding principles but believed in their right to be flexible in following the teachings based on their preferences.

The interviewees who described themselves as less religious considered chores to be non-compulsory and helping with housework as optional. They were selective in performing housework and did not follow the religious teachings closely.

\section{"Islam mentions about shared responsibility. If I can help (in housework), I just help."- Ali, full-time employment, less religious.}

If I see plates in the sink, I will wait till the afternoon, hoping that my wife will wash them. If she does 
not wash them, I will wash them then. I am lazy, so I hope that she will do it." - Jamal, full-time employment, less religious.

"When I know she is free I will ask her to wash the dishes and mop the table because I have something else to do." - Jamal, full-time employment, less religious.

These quotes suggest that Ali and Jamal have similar attitudes in managing housework: they attempted to avoid performing it if possible. Ali used the word 'if', which implies that his involvement in housework is subject to his time availability or mood despite the religious teachings that encourage men to share the responsibility (Tajmazinani, 2021). Similarly, Jamal mentioned his responsibility in performing housework according to the religious teachings, but his attitude was more inclined to him having a backup role than a cosharing role. Their attitudes suggest that these less religious men support a traditional gender role ideology that men should play a backup role in housework, which aligns with the cultural gender norms.

In contrast, those who self-reported as very religious displayed a more egalitarian attitude towards housework. Perhaps the best quote was from Tramizi.

"I take over the dish washing and sweeping floors tasks when she has visitors or incoming calls from friends. We have to tolerate and help each other in housework. I have to help her in doing housework."
- full-time employment, very religious.

The way Tramizi engaged in housework may mean that he takes more initiative in performing housework than his wife. Additionally, Tramizi used the word 'have', which may mean that he sees housework as compulsory work that he needs to do. He reported that based on Islamic religious teachings, his inner self is clean by helping his wife maintain a clean house. This finding suggests that fastidiously performing housework may influence his religious identity, creating a stronger sense of himself as a devoted Muslim. The relationship between religiosity and housework may be mutually reinforcing, not unidirectional.

How men's religiosity influences their attitudes towards housework is illustrated by Ali (less religious), Jamal (less religious) and Tramizi (very religious) and supported by their wives. In the example of Ali (less religious), who seems to have less inclination to share the housework, his wife Aisha described her husband's attitude.

"I have an allergic problem when I use dishwashing liquid to wash dishes. He did not help at all."

"He left the clothes to get wet during rainy days when I was not at home. He will not do it."

Aisha's statement implies that her husband was not helpful. Ali responded that his wife's allergy was inconsistent with his claim that religious teachings encourage shared responsibility. It differs from how 
Tramizi, who considered himself very religious, responded to Nana's backache.

"My husband helps me in housework because I have backache issue. He cleans the house when he is back from work." - Nana, part-time employment, very religious.

Ali, Jamal, Tramizi, Aisha and Nana suggest a link between the strength of religiosity and housework responsibility. This finding is similar to that of research in Xinjiang in urban China (Zang, 2012) and supports findings in Malaysia (Boo, 2018). Focusing on Islam, Boo (2018) and Zang (2012) have argued that males' religiosity is related to their contribution to household labour and that those who have higher religiosity are more likely to engage in housework and less likely to practice traditional household division than those who have lower religiosity.

Consistent with the results for housework, all Malay women and men reported that Islamic religious teachings encourage them to share in taking care of children. However, again, their behaviour depends on the strength of their religiosity. Perhaps the best example was Keri, who self-reported as a very religious Muslim.

"My religion says that both father and mother have to share the childcare work. Although I am busy working, I still help in childcare because this is my responsibility to take care of them."

"Sometimes my wife is invited by friends to attend banquet, I will encourage her to go and I will look after the children. This is not a problem for me. I think it is fun to take care of my children."

These quotes show that Keri has a positive attitude towards sharing childcare with his wife. This finding was consistent with what his wife Azizah said about him. In the interviews, she mentioned that Keri was willing to take care of the children when he was home from work. Azizah was happy because not all husbands were willing to do this. She believed that Islam encourages parents to help each other in childcare to achieve a close relationship and that the husband is blessed if he engages in childcare as he will accumulate good deeds.

By contrast, Ali and Jamal, who considered themselves less religious, had less positive attitudes towards childcare.

"I will ask my wife to handle it when the children wet their pants. I am lazy to do it. If my wife is in the midst of praying, I will do it. If not, I will ask her to do it." - Ali, fulltime employment, less religious.

"When my children want to pee or go to potty, I will ask my wife to clean them. Additionally, I will ask my wife to feed them when the children are hungry." - Jamal, fulltime employment, less religious.

How Ali and Jamal engaged in childcare is consistent with how they engaged in housework. Each man relied more on their wife to take care of their children than Keri 
did. It may also be connected to the strength of their religious beliefs. That Ali did not follow the religious teachings in sharing the childcare is consistent with what his wife, Aisha, reported,

\section{"When I have to attend seminars and he does not have to work on that day, I asked him to look after the children. He refused to do it. Sometimes he just wanted me to bring the children along."}

Aisha's statements suggest that Ali did not follow Islamic religious teachings. He refused to look after the children despite having time available at home. This behaviour was against his claim that religious teachings encourage shared responsibility between couples in taking care of children. In contrast with Ali, Aisha considered herself very religious, and she shouldered the responsibility of teaching children because she believed strongly in the religious teachings on an afterlife.

"I think it [religious teachings] just influenced me. It is my responsibility to teach children. When I die, I will face Allah and answer him. If my husband does not want to fulfil his responsibility in teaching children, he will face Allah when he dies."

Throughout the interviews, the quotes suggest a link between the strength of religiosity and childcare responsibility. This finding seems similar to that of research on Malay families in Malaysia in which Malay men's religiosity is positively associated with fathers' amount and share of childcare time (Boo, 2018).

\section{DISCUSSION}

Unpaid domestic work is a contemporary social issue that affects women's lives (N. N. A. Aziz et al., 2018; Choong et al., 2019). A semi-structured interview with nine Malay couples was used to explore how cultural and religious gender norms have led to gender inequality in the division of housework and childcare in Malaysian families. The interview findings support the gender perspective that women and men act according to defined roles based on gender norms. In this study, gender norms embedded in the Malay culture and Islamic teachings reinforce the traditional model of the male breadwinner and the female homemaker and result in women doing most of the unpaid housework, which is an important factor that prevents women and men from sharing housework equally. In addition to the gender norms, this article highlights that men's share of housework and childcare is related to the strength of their religiosity and gender role ideology.

One main finding is that the division of housework and childcare is underscored by traditional cultural and religious gender norms that produce and reproduce gender inequality in households. In practice, women generally acknowledged that they are responsible for performing housework and childcare because of the gender role expectations in their culture and religion. Women illustrated that 'their place is in 
the kitchen' implies that culture places less value on women's education and career but more value on performing unpaid domestic work (Abdullah et al., 2008; Hamdan, 2009). Women's role is emphasised by cultural gender norms, making them responsible for most of the domestic work despite their educational attainment and labour force participation (Choong et al., 2019; Ministry of Women, Family and Community Development and the United Nations, 2014). Therefore, this affects women's lives (Choong et al., 2019). As a result, they experience gender inequality at home and are restricted from entering the labour force, as illustrated by the women in this study. These findings provide insights into why family responsibility was cited as the main reason women were outside the labour force (Department of Statistics Malaysia, 2019).

As for the men's behaviour, men generally acknowledged that their role is as a family provider and not mainly responsible for housework and childcare. However, regarding religiosity and gender role ideology, some religious men are taking more initiative and are inclined to share the housework and childcare than the less religious men. These findings suggest that religiosity is related to men's gender role ideology and thus influences their share in household labour. This finding is similar to those in other studies in Malaysia (Boo, 2018) and China (Zang, 2012), which suggest that a higher level of religiosity could be an enabler for men to perform more unpaid work.
Notably, gender norms have led to gender inequality in households. The strong emphasis on gender expectations based on cultural and religious gender norms prevents an equal division of household labour despite Malay women having attained higher education qualifications. Thus, achieving Sustainable Development Goal 5.4, which emphasises the importance of sharing household responsibilities, seems difficult.

This study has limitations. The main limitation of the qualitative method used is the small number of respondents. Another limitation is the non-representativeness of the men because the male respondents were invited by their spouses to participate. This limitation excluded male respondents who fulfilled the selection criteria but did not have the opportunity to participate in the interviews. Although the sample of male interviewees was not representative of the Malaysian population, their perceptions and experiences are important and valuable. It would have been very difficult to understand men's behaviours and attitudes towards housework and childcare from their perspectives if the qualitative method had not been adopted.

Notwithstanding these limitations, this article provides insights into the influence of cultural and religious gender norms in the division of household labour among some Malay couples. The interview findings highlight that cultural and religious gender norms prevent achieving an equal division of household labour among some Malay couples. 


\section{CONCLUSION}

Studies on unpaid domestic work are pivotal because the unequal division of household labour affects women's economic status, well-being and life in general. This study's findings suggest that men's and women's roles in unpaid domestic work are shaped by gender norms entrenched in Malay culture and Islamic teachings, which have led to gender inequality occurring among Malay couples. Because of the expected responsibilities defined in cultural and religious gender norms, Malay women perform a disproportional amount of unpaid domestic work. Likewise, men tend to do less unpaid domestic work than women because of their expected roles defined in the cultural and religious gender norms. This study supports the gender perspective that not only does gender role ideology matter but also highlights that religiosity matters when accounting for gender norms in Malay society.

Hence, recognising the importance of cultural and religious gender norms around domestic work as women's work is crucial in narrowing the gender gap in unpaid domestic work. Furthermore, this demonstrates the need for policymakers to understand how gender norms shape the unequal division of household labour and improve gender equality in household labour and economic outcomes and women's wellbeing. Further research on this issue in the Malaysian context is necessary. Researchers could extend this research by investigating couples' experiences of cultural and religious gender norms uncovered during the qualitative interviews. Researchers could also include the other ethnic groups in Malaysia to provide a detailed view of factors that lead to the unequal division of household labour among Malaysian couples.

\section{ACKNOWLEDGEMENT}

Thanks to my supervisors, Professor Lyn Craig and Dr Katrina Moore, for their supervision, support and encouragement throughout this research.

\section{REFERENCES}

Abdullah, K., Noor, N. M., \& Wok, S. (2008). The perceptions of women's roles and progress: A study of Malay women. Social Indicators Research, 89(3), 439-455. https://doi. org/10.1007/s11205-008-9242-7

Adams, M. (2017). Inequality/stratification, gender. The Blackwell Encyclopedia of Sociology, 1-5. https://doi.org/10.1002/9781405165518. WBEOSI037.PUB2

Aziz, A. (2011). Role demands and work-family balance experience in Malaysia: The different moderating effects of collectivism and gender role identity among diverse ethnic groups. University of Technology, Australia.

Aziz, N. N. A., Yazid, Z. N. A., Tarmuji, N. H., \& Samsudin, M. A. (2016). The fourfold taxonomy of work-family balance and wellbeing: The moderating effect of coping Strategy. E-Academic Journal, 5(1), 1-4.

Aziz, N. N. A., Yazid, Z. N. A., Tarmuji, N. H., Samsudin, M. A., \& Majid, A. A. (2018). The influence of work-family conflict and familywork conflict on well-being: The mediating role of coping strategies. International Journal of Academic Research in Business and Social Sciences, 8(4), 259-275. https://doi.org/10.6007/ ijarbss/v8-i4/4012 
Bianchi, S. M., Milkie, M. A., Sayer, L. C., \& Robinson, J. P. (2000). Is anyone doing the housework? Trends in the gender division of household labor. Social Forces, 79(1), 191-228. https://doi.org/10.2307/2675569

Bittman, M., England, P., Folbre, N., Sayer, L., \& Matheson, G. (2003). When does gender trump money? Bargaining and time in household work. American Journal of Sociology, 109(1), 186-214. https://doi.org/10.1086/378341

Blood, R. O., \& Wolfe, D. M. (1960). Husbands \& wives: The dynamics of married living. Free Press.

Boo, H. S. (2018). Ethnicity and religiosity in the gender division of housework and childcare in Malay and Chinese households in Malaysia [Doctoral dissertation, University of New South Wales]. https:/unsworks.unsw.edu.au/fapi/datastream/ unsworks:51104/SOURCE2?view=true

Carlson, D. L., \& Lynch, J. L. (2017). Purchases, penalties, and power: The relationship between earnings and housework. Journal of Marriage and Family, 79(1), 199-224. https://doi.org/ https://doi.org/10.1111/jomf.12337

Choong, C., Firouz, A. M. M., Jasmin, A. F., Noor, N. M., \& Gong, R. (2019). Time to care: Gender inequality, unpaid care work and time use survey. Khazanah Research Institute.

Cislaghi, B., \& Heise, L. (2020). Gender norms and social norms: Differences, similarities and why they matter in prevention science. Sociology of Health \& Illness, 42(2), 407-422. https://doi. org/10.1111/1467-9566.13008

Coltrane, S. (2000). Research on household labor: Modeling and measuring the social embeddedness of routine family work. Journal of Marriage and Family, 62(4), 1208-1233. https:// doi.org/10.1111/j.1741-3737.2000.01208.x

Coverman, S. (1985). Explaining husbands' participation in domestic labor. The Sociological Quarterly, 26(1), 81-97.
Craig, L., \& Brown, J. E. (2017). Feeling rushed: Gendered time quality, work hours, nonstandard work schedules, and spousal crossover. Journal of Marriage and Family, 79(1), 225-242. https:// doi.org/10.1111/jomf.12320

Cunningham, M. (2001). Parental influences on the gendered division of housework. American Sociological Review, 66(2), 184-203. https://doi. org/10.2307/2657414

Department of Statistics Malaysia. (2019). Labour force survey report. https://www.dosm.gov.my/ v1/index.php? $r=$ column/pdfPrev\&id=TlVMbEt BVXBGTi80VjdqZ1JUdVRHdz09

Epstein, M., \& Ward, L. M. (2011). Exploring parentadolescent communication about gender: Results from adolescent and emerging adult samples. Sex Roles, 65(1), 108-118. https://doi.org/10.1007/ s11199-011-9975-7

Ferrant, G., Pesando, M., \& Nowacka, K. (2014). Unpaid care work: The missing link in the analysis of gender gaps in labour outcomes. https:/www.empowerwomen.org/en/resources/ documents/2015/5/unpaid-care-work-themissing-link-in-the-analysis-of-gender-gaps-inlabour-outcomes

Hamdan, D. A. A. (2009). Changes of gender relations in Kuching Malay household. AkademikaJournal of Southeast Asia Social Sciences and Humanities, 77(1), 185-200.

Hochschild, A., \& Machung, A. (2012). The second shift: Working families and the revolution at home. Penguin.

Ismail, 'A., \& Hamjah, S. H. (2012). Kefahaman terhadap kedudukan wanita bekerjaya menurut Islam [An understanding on career women from the perspective of Islam]. Jurnal Al-Hikmah 4, 4, 3-14.

Jamil, Z., Tan, B. P., \& Mahadir, N. B. (2018). Changes in gender ideology in domestic chores among professional Malay Muslim men in dual- 
career families: A study in Kuala Lumpur and Selangor. International Journal of Education, Psychology and Counseling, 3(18), 1-10.

Juhari, R., Yaacob, S. N., \& Talib, M. A. (2013). Father involvement among Malay Muslims in Malaysia. Journal of Family Issues, 34(2), 208227. https://doi.org/10.1177/0192513X12461339

Kaufman, M. (2014). Engaging men, changing gender norms: Directions for gender-transformative action. https://www.unfpa.org/resources/briefengaging-men-changing-gender-norms

Knudsen, K., \& Wærness, K. (2008). National context and spouses' housework in 34 countries. European Sociological Review, 24(1), 97-113. https://doi.org/10.1093/esr/jcm037

Ministry of Women, Family and Community Development and the United Nations. (2014). Study to support the development of national policies and programmes to increase and retain the participation of women in the Malaysian labour force: Key findings and recommendations. https://www.my.undp.org/content/malaysia/ en/home/library/womens_empowerment/ women-in-malaysian-labour-force-study-withundp-2013.html

Noor, N. M. (1999). Roles and women's wellbeing: Some preliminary findings from Malaysia. Sex Roles, 41(3), 123-145. https:// doi.org/10.1023/A:1018846010541

Osman, Z. J. (2013). Malay Muslim academic women in dual-career families : negotiating religious and cultural identities and practices [Doctoral thesis, University of York]. https://etheses. whiterose.ac.uk/13086/1/ZURAINI - PHD -3.pdf
Sayer, L. C. (2016). Trends in women's and men's time use, 1965-2012: Back to the future? In V. K. S. M. Mchale, J. V. Hook, \& A. Booth (Eds.), Gender and couple relationships (pp. 43-77). Springer International Publishing. https://doi. org/10.1007/978-3-319-21635-5_2

Somech, A., \& Drach-Zahavy, A. (2016). Gender role ideology. The Wiley Blackwell Encyclopedia of Gender and Sexuality Studies, 1-3. https://doi. org/10.1002/9781118663219.WBEGSS205

Stratton, L. S. (2020). The determinants of housework time: Boosting the efficiency of household production could have large economic effects. IZA World of Labor 2020, Article 133. https:// doi.org/10.15185/izawol.133.v2

Sukri, A. L., \& Shasrini, T. (2020). The concept of gender equality from the Malay perspective. JournalNX - A Multidisciplinary Peer Reviewed Journal, 6(6), 537-544. https://repo.journalnx. com/index.php/nx/article/view/1302

Tajmazinani, A. A. (2021). Social policy in the Islamic world. Palgrave Macmillan. https://doi.org/ https://doi.org/10.1007/978-3-030-57753-7

United Nations Population Fund, \& Promundo. (2018). Engaging men in unpaid care work: An advocacy brief for eastern europe and central asia. https://menengage.unfpa.org/en/resources/ engaging-men-unpaid-care-work

Wood, J. T. (2014). Gendered lives: Communication, gender, and culture (11th ed.). Cengage Learning.

Zang, X. (2012). Islam, family life, and gender inequality in urban China (First). Routledge, London. 
